\title{
Multiple cutaneous metastases as the first sign of metastatic carcinoma of unknown primary
}

\author{
Sonia Rupal Sharma, Douglas Maslin, Sui-Yen Ah-See, Pamela Todd
}

Dermatology, Addenbrooke's Hospital, Cambridge, UK

\section{Correspondence to} Dr Sonia Rupal Sharma, soniarupal.sharma@nhs.net, sonia.sharma@hotmail.co.uk

Accepted 6 February 2018

\section{DESCRIPTION}

An elderly man with a background of bladder cancer in remission, monoclonal gammopathy of uncertain significance and chronic obstructive pulmonary disease was referred by his general practitioner to the dermatology clinic with enlarging, non-tender cutaneous nodules on his neck, upper back and scalp. The first of these had been noted above the left clavicle 3 months previously during a hospital admission, and had since rapidly increased in size, together with a more recent development of newer 'bumps' on the scalp.

On physical examination there was a $25 \times 20 \mathrm{~mm}$ cutaneous nodule sited above his left clavicle (figure 1A). This nodule was firm but not hard, oval-shaped, mobile, had prominent visible vasculature and no associated surface epidermal change. In addition, there were three similar lesions sited adjacent to each other on the vertex of his scalp, and one macular lesion on his upper back (figure 1B). The diagnosis of multiple cutaneous metastases was suspected, with the differential diagnoses including cutaneous lymphoma. Rapid access imaging and $4 \mathrm{~mm}$ cutaneous punch biopsy were performed.

CT of the head, neck, chest, abdomen and pelvis without contrast, due to iodine allergy, demonstrated a cavitating left upper lobe lung lesion and probable brain metastases, but no definitive primary site (figure 2). A subsequent MRI of the head confirmed the presence of multiple enhancing lesions consistent with metastases (figure 3A,B).

Histological analysis of the scalp nodule confirmed the presence of metastatic carcinoma, with basaloid features and non-specific immunohistochemistry favouring urothelial or hepatobiliary primary. Following discussion at lung multidisciplinary team meeting, it was concluded the cavitating lung

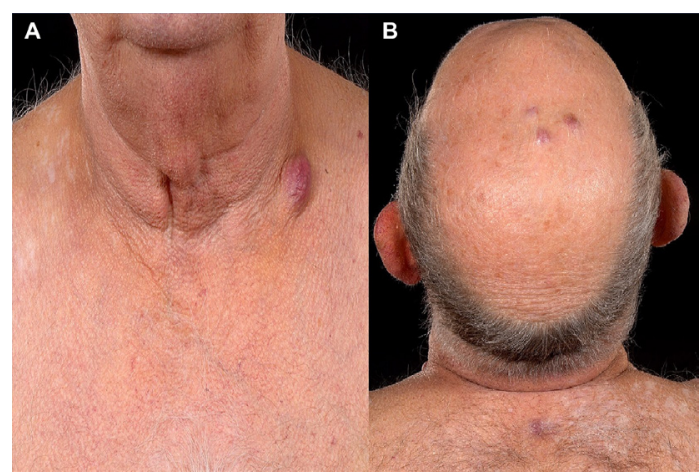

Figure 1 Scalp and neck nodules.

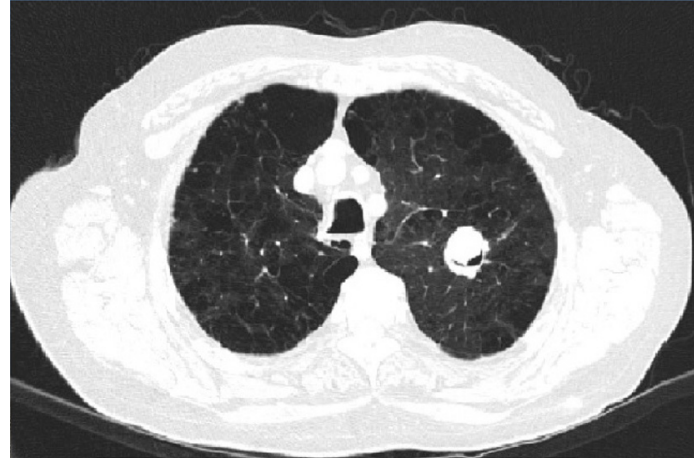

Figure 2 CT chest image demonstrating a $3 \mathrm{~cm}$ nodule with a posterior air crescent.

lesion may represent an aspergilloma, and therefore the diagnosis should be metastatic carcinoma of unknown primary. The patient was referred to the oncology service, who explained to the patient his disease was inoperable and incurable, irrespective of the primary site. Furthermore, the risks and toxicities of palliative chemotherapy were thought to outweigh the benefits of treating his advanced disease. He accepted palliative radiotherapy for the now-symptomatic left-sided neck mass and unfortunately passed away 4 months following diagnosis.

Cutaneous metastases are rare, occurring in $0.7 \%-9 \%$ of patients with cancer. ${ }^{1}$ They usually signal advanced internal malignancy but can be difficult to recognise given their clinical variability. $^{2}$ Typically, cutaneous metastases present as non-tender, oval or round nodules, which can be flesh-coloured, blue-brown or reddish purple in appearance. They can be rubbery or firm in texture and are most likely to present as a

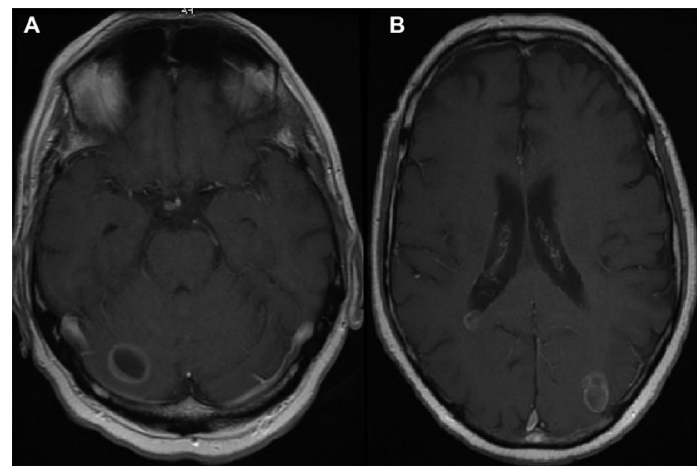

Figure 3 MRI head images identifying multiple ringenhancing lesions consistent with metastatic disease. 
Unfortunately, as our patient passed away 4 months after diagnosis, we were unable to give his perspective on the case. However, looking through the notes, he was in contact with the Macmillan team, and below we have included their consultations with our patient.

"It was a pleasure to see you again today on behalf of the Enhanced Supportive Care clinic. This man is extremely organised and has written his will and planned his funeral (he was prompted to do this following the death of his wife). We have also discussed power of attorney and living well so that he can still keep seeing his disabled daughter who cannot travel and to keep seeing his friends.

Finances are your main concern and the Macmillan Benefits service are planning to contact you again this week to help with your claim. You are also planning to gift some monies to your grandchildren and plan to do this with the help of your son when he arrives from Malta.

From a symptom perspective you are managing fairly well at the moment. Although you do have some pain from your recent fall you are to taking any pain killers for this. Breathlessness can sometimes be a problem but you are used to managing this with the use of occasional nebulisers. In addition to this I have given you some information on breathlessness along with a fan to try.

I understand that you get great support from your local friends whom you often meet in the pub and that your son is coming home from Malta to stay with you. You also find your GP very supportive. We discussed what support you might find useful. At present the thought of Day Therapy at the hospice does not appeal as you want to carry on doing the things you enjoy. If you changed your mind or developed symptoms your GP could refer you on to community palliative care.

You discussed the difficultly of living with an uncertain prognosis which is very difficult for both you and your family. One approach we discussed to managing this was to do the things you enjoy when you feel well enough and not to 'put things off'. Other than spending time with family and friends you were considering some travel - perhaps to Italy".

solitary nodule. ${ }^{3}$ Internal malignancies that most commonly metastasise to the skin include, in generally accepted order of frequency, breast, lung and the colon. ${ }^{3}$ Unmasking the primary malignancy may therefore be a difficult task. The most common cutaneous metastases from previously unknown primary malignancies arise from kidney, lung, thyroid or ovarian tumours. ${ }^{3}$ This combination of factors contributes to the delay in diagnosis and poor prognosis.

\section{Learning points}

- Cutaneous metastases are an uncommon occurrence, and to the inexperienced physician may appear to be harmless; therefore, a high clinical suspicion is needed.

- A rapidly growing cutaneous nodule should be regarded as suspicious for metastatic disease, and an urgent dermatological opinion should be sought to allow early detection.
Contributors SRS contributed to the conception and design of the article, the analysis and interpretation of data, and the final approval of the version published. DM contributed to the revision of the article for important intellectual content.

S-YA-S and PT were responsible for clinical care of the patient and the final approval of the version published.

Competing interests None declared.

Patient consent Not required.

Provenance and peer review Not commissioned; externally peer reviewed.

(C) BMJ Publishing Group Ltd (unless otherwise stated in the text of the article) 2018. All rights reserved. No commercial use is permitted unless otherwise expressly granted.

\section{REFERENCES}

1 Junqueira AL, Corbett AM, Oliveira Filho J, et al. Cutaneous metastasis from gastrointestinal adenocarcinoma of unknown primary origin. An Bras Dermatol 2015;90:564-6.

2 Karde S, Sharma J, Ramesh N, et al. Cutaneous metastases as initial presentation of malignancy. BJR Case Rep 20172;2:0170059.

3 Griffiths C, Barker J, Bleiker T, Chalmers R, Creamer D, eds. Rook's Textbook of Dermatology. 9 edn. Oxford: Wiley-Blackwell, 2016.

Copyright 2018 BMJ Publishing Group. All rights reserved. For permission to reuse any of this content visit

http://group.bmj.com/group/rights-licensing/permissions.

BMJ Case Report Fellows may re-use this article for personal use and teaching without any further permission.

Become a Fellow of BMJ Case Reports today and you can:

- Submit as many cases as you like

- Enjoy fast sympathetic peer review and rapid publication of accepted articles

- Access all the published articles

- Re-use any of the published material for personal use and teaching without further permission

For information on Institutional Fellowships contact consortiasales@bmjgroup.com

Visit casereports.bmj.com for more articles like this and to become a Fellow 